This item was submitted to Loughborough's Research Repository by the author.

Items in Figshare are protected by copyright, with all rights reserved, unless otherwise indicated.

\title{
Effect of microneedles on transdermal permeation enhancement of amlodipine
}

\section{PLEASE CITE THE PUBLISHED VERSION}

http://dx.doi.org/10.1007/s13346-017-0361-z

\section{PUBLISHER}

Springer (C) Controlled Release Society

VERSION

AM (Accepted Manuscript)

\section{PUBLISHER STATEMENT}

This work is made available according to the conditions of the Creative Commons Attribution-NonCommercialNoDerivatives 4.0 International (CC BY-NC-ND 4.0) licence. Full details of this licence are available at: https://creativecommons.org/licenses/by-nc-nd/4.0/

\section{LICENCE}

CC BY-NC-ND 4.0

\section{REPOSITORY RECORD}

Nalluri, Buchi N., Chandrateja Uppuluri, Jyothirmayee Devineni, Atul Nayak, Karthik J. Nair, Benjamin R. Whiteside, and Diganta Bhusan Das. 2017. "Effect of Microneedles on Transdermal Permeation Enhancement of Amlodipine". figshare. https://hdl.handle.net/2134/24669. 


\section{EFFECT OF MICRONEEDLES ON TRANSDERMAL PERMEATION ENHANCEMENT OF AMLODIPINE}

Chandra Teja Uppuluri ${ }^{1}$, Jyothirmayee ${ }^{1}{ }^{1}$, Atul Nayak ${ }^{2}$, Karthik J. Nair ${ }^{3}$, Benjamin R. Whiteside ${ }^{3}$, Diganta B. Das ${ }^{2}$, Buchi N. Nalluri*1

${ }^{1}$ Department of Pharmaceutics, KVSR Siddhartha College of Pharmaceutical Sciences, Vijayawada-520010, AP, India

${ }^{2}$ Department of Chemical Engineering, Loughborough University, Loughborough LE11 3TU, UK

${ }^{3}$ Department of Engineering and Informatics, University of Bradford, Bradford BD7 1DP, UK

*Corresponding Author

Buchi N. Nalluri, Professor and Director for PG Studies and Research,

KVSR Siddhartha College of Pharmaceutical Sciences, Vijayawada-520010, AP, India

E-mail: buchinalluri@yahoo.com

Telephone: +91-9618394959 


\section{ABSTRACT}

The present study was aimed to investigate the effect of microneedle (MN) geometry parameters like length, density, shape and type on transdermal permeation enhancement of Amlodipine (AMLO). Two types of MN devices viz. AdminPatch ${ }^{\circledR}$ arrays (ADM) (0.6, 1.2 and $1.5 \mathrm{~mm}$ lengths) and laboratory fabricated polymeric MNs (PM) of $0.6 \mathrm{~mm}$ length were employed. In the case of PMs, arrays were applied thrice at different places within a $1.77 \mathrm{~cm}^{2}$ skin area (PM-3) to maintain the MN density closer to $0.6 \mathrm{~mm}$ ADM. Scaling analyses was done using dimensionless parameters like concentration of AMLO $\left(\mathrm{C}_{\mathrm{t}} / \mathrm{C}_{\mathrm{s}}\right)$, thickness $(\mathrm{h} / \mathrm{L})$ and surface area of the skin $\left(\mathrm{Sa} / \mathrm{L}^{2}\right)$. Micro-injection moulding technique was employed to fabricate PM. Histological studies revealed that the PM, owing to their geometry/design, formed wider and deeper microconduits when compared to ADM of similar length. Approximately 6.84 and 6.11 fold increase in the cumulative amount (48 h) of AMLO permeated was observed with $1.5 \mathrm{~mm}$ ADM and PM-3 treatments respectively, when compared to passive permeation amounts. Good correlations $\left(\mathrm{R}^{2}>0.89\right)$ were observed between different dimensionless parameters with scaling analyses. The enhancement in AMLO permeation was found to be in the order of $1.5 \mathrm{~mm} A D M \geq P M-3>1.2 \mathrm{~mm}$ ADM $>$ $0.6 \mathrm{~mm}$ ADM $\geq \mathrm{PM}-1>$ Passive. The study suggests that MN application enhances the AMLO transdermal permeation and the geometrical parameters of MNs play an important role in the degree of such enhancement.

Keywords: Amlodipine, Histological examination, Microneedle geometry, Scaling analyses, Transdermal permeation. 


\section{ACKNOWLEDGEMENTS}

The authors are thankful to Arene Life Sciences, Hyderabad, for providing a gift sample of AMLO, to Dr. Naveen, Department of Pathology, Dr. Pinnamaneni Siddhartha Institute of Medical Sciences and Research Foundation, Vijayawada, for providing the required facilities for taking histological sections of skin samples and also to the Siddhartha Academy of General and Technical Education, Vijayawada, for providing necessary facilities to carry out the research work. The authors also extend their sincere thanks to Department of Science and Technology (DST), Ministry of Science and Technology, Govt. of India and the British Council, London, UK, for funding this research work under the DST-UKIERI scheme (DST/INT/UK/P-60/2014). 


\section{EFFECT OF MICRONEEDLES ON TRANSDERMAL PERMEATION ENHANCEMENT OF AMLODIPINE}

\section{ABSTRACT}

The present study was aimed to investigate the effect of microneedle (MN) geometry parameters like length, density, shape and type on transdermal permeation enhancement of Amlodipine (AMLO). Two types of MN devices viz. AdminPatch ${ }^{\circledR}$ arrays (ADM) (0.6, 1.2 and $1.5 \mathrm{~mm}$ lengths) and laboratory fabricated polymeric MNs (PM) of $0.6 \mathrm{~mm}$ length were employed. In the case of PMs, arrays were applied thrice at different places within a $1.77 \mathrm{~cm}^{2}$ skin area (PM-3) to maintain the MN density closer to 0.6 mm ADM. Scaling analyses was done using dimensionless parameters like concentration of AMLO $\left(\mathrm{C}_{\mathrm{t}} / \mathrm{C}_{\mathrm{s}}\right)$, thickness $(\mathrm{h} / \mathrm{L})$ and surface area of the skin $\left(\mathrm{Sa} / \mathrm{L}^{2}\right)$. Micro-injection moulding technique was employed to fabricate PM. Histological studies revealed that the PM, owing to their geometry/design, formed wider and deeper microconduits when compared to ADM of similar length. Approximately 6.84 and 6.11 fold increase in the cumulative amount (48 h) of AMLO permeated was observed with $1.5 \mathrm{~mm}$ ADM and PM-3 treatments respectively, when compared to passive permeation amounts. Good correlations $\left(\mathrm{R}^{2}>0.89\right)$ were observed between different dimensionless parameters with scaling analyses. The enhancement in AMLO permeation was found to be in the order of $1.5 \mathrm{~mm}$ ADM $\geq$ PM-3 $>1.2 \mathrm{~mm}$ ADM $>$ 0.6mm ADM $\geq \mathrm{PM}-1>$ Passive. The study suggests that MN application enhances the AMLO transdermal permeation and the geometrical parameters of MNs play an important role in the degree of such enhancement.

Keywords: Amlodipine, Histological examination, Microneedle geometry, Scaling analyses, Transdermal permeation. 


\section{INTRODUCTION}

Delivering medicines to the systemic circulation through the skin is considered as a good alternative to conventional oral or parenteral routes of administration owing to the advantages like lack of pain, ease of administration, etc., thus improving patient compliance; while improving the overall therapeutic gain of the drug by bypassing the gastrointestinal tract, avoiding hepatic first pass metabolism, maintaining a constant and prolonged drug level in plasma, etc $[1,2]$. These advantages make transdermal drug delivery particularly interesting and beneficial in the management of conditions like hypertension that impose the burden of repeat dosage and chronic administration of medicines via conventional routes.

Hypertension, reputed as 'the silent killer', is affecting about 70 million people and accounts for 9.4 million deaths worldwide every year. It is arguably the most important risk factor for coronary heart disease and stroke [3, 4]. Amlodipine besylate (AMLO) is a calcium channel blocker used to treat hypertension and associated cardiovascular diseases. On oral administration, it undergoes extensive first pass metabolism and has an oral bioavailability (BA) of only $60-65 \%$ and is also associated with several side effects such as nausea, stomach pain, flushing, etc., $[5,6]$. Hence, transdermal delivery of AMLO may alleviate the side effects, improve the BA and overall patient compliance towards medication. However, AMLO, with an n-octanol/water $\log P$ values of $0.65,1.33$ and was reported to be too hydrophilic to permeate through skin at significant rates without the application of any transdermal permeation enhancement technique [7].

Several attempts have been made to overcome the excellent barrier properties of the stratum corneum, the outer most layer of skin, to enhance transdermal delivery of AMLO. Use of different chemical permeation enhancers like sodium lauryl sulphate, Alcohol, propylene 
glycol, etc. was reported to increase the transdermal permeation of AMLO to certain extent, however, not clinically significant [7-10].

Microneedles (MN), a novel transdermal permeation enhancement technique, are minimally invasive and potentially painless method of overcoming the barrier properties of skin for enhanced delivery of drugs [11]. This technique has many advantages when compared to hypodermic injection, is believed to make conduits of micrometer dimensions in skin layers in the epidermal layers (especially, SC) and thus believed to enhance the transdermal permeation of drugs [12]. MNs are known to improve the permeation of drug molecules, including macromolecules like insulin, growth hormone, etc [13-15].

Monika et al., (2013), studied the effect of stainless steel solid microneedles and microneedle rollers on percutaneous penetration of verapamil hydrochloride and amlodipine besylate [16]. The study inferred a statistically significant enhancement in transdermal permeation of both molecules following MN application. Even though two types of MN devices viz. array and rollers were employed in the study, no further evaluation was carried out to determine their relative efficiency on permeation enhancement of AMLO. Transdermal permeation enhancement of drugs using microneedle technology is a complex phenomenon and it has been reported in the literature that several geometric parameters of MNs like shape, dimensions, density of MN on the device and type etc. play important roles in enhancing the transdermal permeation of drugs [17]. There is also interplay of the effect of these variables and, as such, their effects on the permeation of a drug molecule are generally non-intuitive. As a result, their effects are best studied for specific case $[17,18]$.

Motivated by this idea, the present study was designed as a systematic approach to explore the effect of MN geometry on the extent of AMLO transdermal permeation enhancement. Two types of MN devices viz. commercially available AdminPatch ${ }^{\circledR}$ arrays (ADM) (0.6, 1.2 and $1.5 \mathrm{~mm}$ length) and laboratory fabricated polymeric MN arrays (PM) (0.6 mm length) of 
different MN densities were employed in this investigation (Fig. 1). A number of different techniques like etching, lithography and moulding were discussed widely in the literature for the manufacture of MNs of different dimensions (100-1800 $\mu \mathrm{m}$ in length), shapes with different materials (plastics, silicon, ceramics, metals, etc.). Injection moulding offers several advantages in terms of ease of scalability for bulk manufacture, range of materials and good reproducibility [19]. In this study, micro-injection moulding was employed for fabrication of the polymeric MN arrays (PM) using PEEK LT-3 (polyether ether ketone) as reported in previous paper [20].

Surface visualization and histological evaluation of skin samples were carried out to confirm and to study formation miroconduits by application of either types of MN devices. Moreover, the obtained AMLO permeation data was subjected to mathematical treatment using scaling analyses to obtain correlations between dimensionless parameters like amount of AMLO permeated $\left(\mathrm{C}_{t} / \mathrm{C}_{\mathrm{s}}\right)$ and various variables of the study like surface area $\left(\mathrm{Sa} / \mathrm{L}^{2}\right)$ and thickness $(\mathrm{h} / \mathrm{L})$ of skin based on the principles of Buckingham $\pi$ theorem as described in a previous papers in order to gain insights into the phenomenon of AMLO transport behaviour and distribution in the skin layers [21, 22].

\section{MATERIALS AND METHODS}

\section{Materials}

AdminPatch ${ }^{\circledR}$ MN arrays were purchased from AdminMed, Sunnyvale, U.S.A. Amlodipine besylate (AMLO) was obtained from Arene Life Sciences, Hyderabad, India; Sodium chloride, isopropyl alcohol, propylene glycol and 1\%w/v Safranin solution from Loba Chemie, Mumbai, India; Formic acid, acetonitrile, methanol and HPLC water from Merck Specialities Pvt. Ltd, Mumbai, India; Haematoxylin and Eosin stain from Sigma-Aldrich, 
Bengaluru, India. All the reagents and chemicals used in the study were of HPLC grade. Pig ear skin was obtained from local abattoirs.

\section{Fabrication of Polymeric MN (PM)}

MN array components consisted of 25 conical needles, each $0.6 \mathrm{~mm}$ in length with a base diameter of $0.3 \mathrm{~mm}$, in a 5 x 5 array over a 0.5 x $0.5 \mathrm{~cm}^{2}$ area, supported by a circular substrate of diameter $17.5 \mathrm{~mm}$ and thickness $0.5 \mathrm{~mm}$. Moulding of these components was performed using a Wittmann-Battenfeld Micro-Power 15 micro-injection moulding machine as shown in Fig. 2A. This machine offers a high repeatability, accurate dosing, clean room facility, and robotic component handling which is ideal for the bulk manufacture of MNs. The MN mould insert (Fig. 2B) was made out of Stavax ESR (Bohler-Uddeholm Corp, Elgin, USA). Sink electrical discharge machining (EDM) was used to create negative MN features into the insert and was outsourced to Isometric tool and design Inc. (New Richmond, USA).

The polymer used for this study is PEEK (Polyetheretherketone) LT-3 grade material, which is an FDA-approved semi-crystalline biomaterial manufactured by Invibio Inc, Lancashire, UK and is widely employed for medical use. The attractive characteristics of PEEK LT-3 for this application include its excellent processability, dimensional stability, mechanical strength, chemical resistance and resistance to gamma and ethylene oxide sterilisation methods. To ensure the moisture content of the material was suitable for processing, the material was dried at a temperature of $150{ }^{\circ} \mathrm{C}$ for 4 hours prior to moulding.

Moulding trials were performed to optimise the process parameters based on measurement of the needle dimensions and substrate flatness. The optimised parameters for the moulding of PM are shown Table 1. Once the process was stabilised, samples were collected for the subsequent experimental work. 


\section{MN dimensional evaluation}

\section{Scanning electron microscope:}

A Hitachi TM-3000 table-top Scanning Electron Microscope was used for analysis of the MN insert and needle geometry. The Hitachi TM-3000 has a magnification from 15X to 30000X, sample chamber of $700 \mathrm{~mm}$ diameter and $50 \mathrm{~mm}$ thickness. It features $5 \mathrm{kV}, 15 \mathrm{kV}$ and analysis observation modes. Because of the high aspect ratio and low contrast of the MNs, analysis mode was used for imaging. The major advantage of using TM 3000 SEM was it works under low vacuum and does not need specimen coating.

\section{Confocal laser microscope:}

It is very important to measure the tip radius and height of the MNs and the most common methods used are optical or electron microscopy. Because of its steep and complex structures, a 3D image analysis gives a better measurement of the needle geometry and quality control. In this study an Olympus vertical scanning laser confocal microscope LEXT OLS 4000 was used to accurately measure the tip radius and height of MN arrays.

The device offers a broad magnification range from $108 \mathrm{X}$ to $17280 \mathrm{X}$ and the exact $3 \mathrm{D}$ reconstruction of the MNs. The confocal laser microscope LEXT scans the surfaces with a laser beam with the wavelength of $405 \mathrm{~nm}$ thus allowing submicron visualization of material and component surfaces with the resolution of down to $0.10 \mu \mathrm{m}$. Measurements were taken with the $20 \mathrm{X}$ lens using the wide range stitching feature with 20 percent overlap to produce a measurement area of $5 \mathrm{~mm} \times 5 \mathrm{~mm}$. A five level brightness switch was enabled to accurately illuminate the specimen.

\section{Atomic force microscope:}

The most important feature of the $\mathrm{MN}$ is that the tip has to be sharp in order to effectively pierce the skin. So as to confirm the measurements made from confocal laser microscope, AFM (MFP-3D Asylum Research Santa Barbara, USA) was used to measure the tip radius of 
the MNs. All AFM scans were made using an MFP-3D scanner from Asylum Research, Santa Barbara, USA. Silicon nitride cantilever tips (Applied Nanostructures, Santa Clara, USA) with a tip radius of $15 \mathrm{~nm}$ and spring constant of $0.3 \mathrm{Nm}$ were used. Images were interpreted using integrated MFP-3D ${ }^{\mathrm{TM}}$ Igor software (USA). Errors in the piezo-linearity were corrected for by using zero and first order flattening.

\section{HPLC method}

RP-HPLC-PDA method was developed specifically for the analysis of AMLO in the transdermal permeation samples. A Shimadzu Prominence HPLC system provided with DGU-20A3 degasser, LC-20AD binary pumps, SIL-20AHT auto sampler and SPD-M20A PDA detector was used for analysis of the samples. Data acquisition was carried out using LC solutions software. Separation was achieved on an Inertsil ODS column $(250 \times 4.6 \mathrm{~mm}$; $5 \mu \mathrm{m})$. The mobile phase comprised of $0.01 \% \mathrm{v} / \mathrm{v}$ formic acid : acetonitril 70:30 (v/v) at a flow rate of $1.2 \mathrm{~mL} / \mathrm{min}$ with an injection volume of $20 \mu \mathrm{L}$ and the eluents were monitored at $238 \mathrm{~nm}$. The developed method was validated as per ICH guidelines.

\section{Solubility studies}

The solubility of AMLO was studied in different vehicle combinations of propylene glycol (PG), polyethylene glycol-400 (PEG), and saline (S) at 70:30, 80:20 and 90:10\% v/v ratios. To each vehicle system, excess amount of AMLO was added and vortexed for 1 min in order to obtain a saturated solution and the solutions were equilibrated at $37^{\circ} \mathrm{C}$ in an orbital shaker for $24 \mathrm{~h}$. After equilibration, the samples were centrifuged at $3000 \mathrm{rpm}$ for $10 \mathrm{~min}$ and filtered through a nylon syringe filter $(0.45 \mu \mathrm{m})$ and all the samples were appropriately diluted and analysed by HPLC method. 


\section{Skin Preparation}

Pig ears were collected from the local abattoirs immediately after animals were killed by electric current. The ears were transported to the laboratory in a cooling box without previous treatment. In the laboratory, the pig ears were washed carefully with distilled water and the hair was removed from the external part of pig ear using an electrical hair clipper. Carefully the full-thickness skin from the external part of the pig ear was separated from underlying cartilage using a scalpel and excess fat underlying the skin was removed to a thickness of $1.2 \mathrm{~mm}$ was employed for the in vitro transdermal permeation studies. The dermis side was wiped with isopropyl alcohol to remove the residual adhering fat. Processed skin samples were individually wrapped in plastic bags without air entrapment and stored in a deep freezer at $-20^{\circ} \mathrm{C}$ until further use.

\section{Application of MNs on skin samples}

Prior to the in vitro skin permeation experiments, the skin samples were allowed to be brought to room temperature and then the skin surface was carefully washed with saline. Two types of MN devices viz, $\mathrm{ADM}(0.6,1.2$ and $1.5 \mathrm{~mm})$ and PM $(0.6 \mathrm{~mm})$ were used to poke the skin surface under thumb pressure. In the case of PM, both single (PM-1) and triple (PM-3) insertions at different places within a $1.77 \mathrm{~cm}^{2}$ skin area (PM-3) were made in order to maintain the MN density closer to ADM of $0.6 \mathrm{~mm}$ length as shown in Fig. 1 . The MNs were periodically checked during this process for potential damage using a stereomicroscope.

\section{Surface visualization and histological examination of the skin samples}

To visually confirm the disruption of skin layers by the MNs, the arrays were pressed over the pig ear skin under thumb pressure and held for $1 \mathrm{~min}$. Then the skin was stained with safranin dye (1\% w/v in water) and wiped with isopropanol cotton swabs for the 
identification of the microconduits formed. In the case of the histological studies, the skin section samples with and without $\mathrm{MN}$ treatments were prepared after staining with haematoxylin and eosin for visualization of skin layers and to display a clear indentation by MN penetration. The sections were observed under a microscope (Olympus; Noida, India). The width and depth of microconduits formed were also calculated in triplicate ( $\mathrm{n}=3$ skin samples for each MN) with the help of Toup View 3.2 Software (Irwin, U.S.A). For control, skin samples without MN treatment were also prepared.

\section{In Vitro Skin Permeation Studies}

The in vitro transdermal permeation studies were performed using a vertical type Franz diffusion cell apparatus fitted with a water circulation system, a water heater and an eight stage magnetic stirrer (Orchid Scientifics, Nasik, India). Franz diffusion cells with an effective diffusion area of $1.77 \mathrm{~cm}^{2}$ and a receptor volume of around $14 \mathrm{~mL}$ were used. Saline was used as the receptor fluid. Pig ear skin was mounted between the donor and receptor cells with the SC facing towards the donor cell. The receptor medium was stirred for uniform drug distribution at a speed of $600 \mathrm{rpm}$ throughout the experiment. Care was taken to prevent the entrapment of air bubbles at the interface of the skin (dermis) and the receptor solution. The surface of the skin was maintained at $32^{\circ} \mathrm{C}$ using a circulating water bath. After equilibration, $500 \mu \mathrm{L}$ of donor solutions containing excess amount of AMLO were applied on to the skin (in the donor compartment). Samples (500 $\mu \mathrm{L})$ were withdrawn from the receptor fluid at six hour increments up to 48 hours and replaced with the fresh saline to maintain a constant volume. All the samples were stored at $4^{\circ} \mathrm{C}$, prior to the HPLC analysis.

The cumulative permeation profiles were plotted for the cumulative amount of drug permeated $\left(\mathrm{nmoL} / \mathrm{cm}^{2}\right)$ as a function of time, for untreated and microneedle treated skin. The 
flux values and the respective lag times were obtained from the slope and the X-intercept of the steady state portion of the cumulative permeation profiles. Apparent permeability and diffusion coefficient values were computed from Fick’s first law of diffusion:

$$
\frac{1}{A}\left(\frac{d M}{d t}\right)=J_{s}=K_{p} \Delta C
$$

$\boldsymbol{J}_{\boldsymbol{s}}$ is the steady-state flux (nmoL/cm²/hr), $\boldsymbol{M}$ is the cumulative amount of drug permeating the skin $\left(\mathrm{nmoL} / \mathrm{cm}^{2}\right), \boldsymbol{A}$ is the area of the skin $\left(1.77 \mathrm{~cm}^{2}\right), \boldsymbol{K}_{\boldsymbol{p}}$ is the apparent permeability coefficient $(\mathrm{cm} / \mathrm{hr})$, and $\boldsymbol{\Delta C}$ is the difference in concentrations of AMLO in the donor and receiver. Sink conditions were maintained in the receiver throughout the experiment and hence $\Delta \boldsymbol{C}$ was approximated to be the drug concentration in the donor compartment.

Enhancement ratios were also computed to evaluate the relative efficiency of different MNs on the AMLO skin permeation enhancement. The enhancement ratios were calculated as follows:

$$
\text { Enhancement Ratio }=\frac{\text { Cumulative amount or Flux obtained after MN application }}{\text { Cumulative amount or Flux obtained from passive studies }}
$$

\section{AMLO content in skin}

After the completion of the permeation studies, skin samples were studied for drug disposition. The skin tissue exposed to the donor solution was cut with a scalpel and washed with filtered water and blotted with a paper towel in order to remove the drug which had adhered to the surface. Then skin was minced with a scalpel, and placed in a pre-weighed vial. The drug was extracted from the skin by equilibrating with $5 \mathrm{~mL}$ of acetonitrile at $32^{\circ} \mathrm{C}$ in an orbital shaker. The solutions were then analyzed by HPLC to determine the AMLO content. 


\section{Scaling analyses}

Dimensionless correlations between the amount of AMLO permeated $\left(\mathrm{C}_{t} / \mathrm{C}_{\mathrm{s}}\right)$ and other variables such as the thickness $(\mathrm{h} / \mathrm{L})$ and the surface area $\left(\mathrm{Sa} / \mathrm{L}^{2}\right)$ of the skin were made in order to gain insights into the overall phenomenon of AMLO transdermal permeation enhancement by MN application. The scaling analyses were carried out based on the principles of the Buckingham $\pi$ theorem where it is defined that the dimensionless concentration of a drug, which permeates through skin, can be defined in terms of key nondimensional parameters (e.g., MN lengths) using the procedures described in previous papers $[21,22]$.

Eq.1 describes the relationship of all the model parameters used for such analyses (Table 2).

$$
\frac{C_{t}}{C_{s}}=K\left[\frac{S_{a} L^{4} K_{e}}{V_{d} h D}\right]^{n}
$$

Where, ' $\mathrm{K}$ ' is a dimensionless constant and ' $\mathrm{n}$ ' is an unknown power; $\mathrm{C}_{t}$ and $\mathrm{C}_{\mathrm{s}}$ are the amount of AMLO permeated at a given time $\mathrm{t}(48 \mathrm{~h})$ and the amount of drug loaded in the donor compartment for diffusion (surface concentration on skin); $S_{a}$ is the surface area of skin available for diffusion; $L$ is the length of microneedles; $K_{e}$ and $V_{d}$ are the first order elimination constant and the volume of receptor fluid; ' $h$ ' is the thickness of skin and D is the diffusion coefficient of AMLO in skin.

Using Eq.1, the correlations between the dimensionless AMLO concentration $\left(\mathrm{C}_{t} / \mathrm{C}_{\mathrm{s}}\right)$ against the dimensionless parameters of the study $\left(\mathrm{h} / \mathrm{L}\right.$ and $\mathrm{S}_{\mathrm{a}} / \mathrm{L}^{2}$ ) have been established considering that all other variables remain unchanged.

\section{Statistical analysis of the data}

Results of the experimental data were subjected to statistical analysis by one way ANOVA (using Fischer's LSD post hoc test) using SYSTAT 13 software (Systat Software Inc., San Jose, USA). Results with a $p$ value of less than 0.05 were considered to have statistically 
significant variance. Mean of replicate measurements $(n=3)$ with corresponding standard deviation (SD) was used to represent the data and to plot the graphs. 


\section{RESULTS AND DISCUSSION}

\section{Fabrication and characterization of PM}

Polymeric MN arrays (PM) were fabricated using (PEEK)-LT3 (polyether ether ketone) using micro-injection moulding technique, with $25 \mathrm{MN}$ on each array ( $\mathrm{MN}$ density) and the array base thickness of $300 \mu \mathrm{m}$. The dimensions of PM, determined using a 3D confocal imaging (Fig. 3A) and scanning electron microscopy (SEM) (Fig. 3B), were found to be 556 $\pm 30 \mu \mathrm{m}$ in height with a tip radius of $32 \pm 8 \mu \mathrm{m}$, with a base thickness of $300 \mu \mathrm{m}$ and $\mathrm{MN}$ interspacing of approximately $1 \mathrm{~mm}$ at the base.

For better comparison and understanding of the difference in the shape/design between PM and ADM devices, 3D confocal images of $0.6 \mathrm{~mm}$ ADM were given in Fig. 3C. Also the difference in base thickness among the devices can be clearly observed from Fig. 1. The various geometry parameters of both types of MN devices were given in Table 3.

The dimensions of the PM were found to be consistent and repeatable with good tip shape, confirming the complete filling of the PEEK into the MN insert cavity under the maintained processing conditions (Table 1) and the technique used is reliable for the bulk manufacture of PMs. Compression tests of PM on a steel plate using Bose Electroforce 3100 instrument with a $225 \mathrm{~N}$ load cell and Wintest ${ }^{\circledR}$ software (Bose, MN, USA) revealed that the PMs were able to withstand compression forces of up to $8 \mathrm{~N}$ [20].

\section{Analytical Method}

A rapid and sensitive HPLC-PDA method was developed for the selective quantification of AMLO in transdermal permeation studies. Under the developed LC conditions, AMLO eluted at 3.9 min with good peak shape. Also, the specificity of the method to AMLO was demonstrated by the UV spectrum and the peak purity index curves. The method was validated as per ICH guidelines and complied with all the requirements. The method was 
successfully employed for the quantitative estimation of AMLO in various samples throughout the study.

\section{Solubility Studies}

Solubility studies for AMLO were performed with a view to select appropriate donor vehicle for conducting in vitro skin permeation studies. PG:S and PEG:S combinations at 70:30, 80:20 and 90:10 \%v/v were studied for AMLO solubility. The solubility data obtained was shown in Fig. 4. Solubility of AMLO was relatively higher in PG:S when compared with PEG:S combinations $(p>0.05)$ (Fig. 4). The solubility of AMLO increased as the water content of the vehicle system increased, in the order 90:10<80:20<70:30 \% v/v in both PG:S and PEG:S combinations. However, a significant difference was not observed among the vehicle combinations $(p>0.05)$. PG:S at 70:30\%v/v was selected for the AMLO in vitro skin permeation studies.

\section{Surface visualization and histological examination of skin samples}

In order to visually confirm the ability of disruption of skin layers by MNs, the arrays were pressed over the pig ear skin under thumb pressure and held for 1 min and the skin samples were stained with safranin $(1 \% \mathrm{w} / \mathrm{v})$. The skin samples showed clear distinctions in the number of the microconduits formed as per the length and density of MNs in ADM and PM devices (Fig. 5).

Histological section images of skin treated with MNs were shown in Fig. 6. From the images, the stratum corneum disruption and the formation of microconduits across skin layers was clearly evident. The average penetration depth (vertical) $(n=3)$ of the MNs was found to be $180.26 \pm 30.39,400.85 \pm 20.83,478.48 \pm 67.72$ and $338.20 \pm 22.66 \mu \mathrm{m}$ for ADM $(0.6$, 1.2, $1.5 \mathrm{~mm}$ ) and PM, respectively. The average penetration depth (vertical) was about 2535\% for ADM and 55-60\% for the PM MN lengths (Fig. 6). Even though the length of the 
MNs differ in ADM, the percentage of MN penetration is almost same, which is an indication of uniformity in thumb pressure under which MNs were applied at different times.

With the ADM devices, as the length of the MNs increased the penetration depth also increased. However, the microconduits were found to be wider and deeper with PM when compared to ADM of similar lengths i.e. $0.6 \mathrm{~mm}$. These differences in the efficiency of creating microconduits in skin layers between the two types of MN devices (ADM and PM) may be attributed to the differences in geometry parameters like shape, design and type of fabricating material. Regarding the shape/design, PM being conical (3D) in shape, the microconduits formed by PM were wider, while that with ADM looks merely like a cut on the skin (2D) as the arrays of ADM are low in thickness (2D) (Fig. 3). Furthermore, owing to the sturdy and thick base (when compared to ADM) that supports the solid PM (Fig. 1), the effective resistance (because of the viscoelastic nature) of the skin during application of arrays may be less for PM, while the ADM might have experienced greater resistance which is because of their thin base and array design [23], resulting in a relatively shallow penetration with similar MN lengths (0.6 mm ADM).

\section{In vitro permeation studies}

The comparative in vitro pig ear skin permeation profiles of AMLO without and with MN application were shown in Fig. 7. Various AMLO permeation parameters viz. cumulative amount permeated at the end of $48 \mathrm{~h}$, steady state flux, lag time, permeability and diffusion coefficients without and with microneedle treatment were given in Table 4.

Significant enhancement in AMLO permeation was observed after MNs application onto the skin $(p<0.05)$ when compared to passive permeation studies (Fig. 7). A 2.00, 3.56 and 6.84 fold increase in the cumulative amount (48 h) of AMLO permeated was observed with 0.6, 1.2 and $1.5 \mathrm{~mm}$ ADM treatments, respectively, when compared to passive permeation amount. A similar trend was observed with other permeation parameters like permeability 
and diffusion coefficient values (Table 4). Significant reduction in the lag time was observed after application of 1.2 and $1.5 \mathrm{~mm}$ ADM when compared to that with passive permeation studies $(p<0.05)$. However, there is no statistically significant difference between passive and $0.6 \mathrm{~mm}$ and $1.2 \mathrm{~mm}$ ADM treatments in terms of lag time ( $p>0.05)$.

The AMLO flux values were found to be in the order of $1.5 \mathrm{~mm}>1.2 \mathrm{~mm}>0.6 \mathrm{~mm}>$ passive with ADM treatments $(p<0.05)$. A 5.29 fold increase in AMLO flux was observed with the $1.5 \mathrm{~mm}$ when compared to passive studies. It was observed that the enhancement of AMLO permeation was only marginal with the application of $0.6 \mathrm{~mm}$ ADM when compared to passive studies (Fig. 7). This may be due to the fact that the skin disruption/penetration caused by $0.6 \mathrm{~mm}$ ADM was less as supported by histological section images (Fig. 6). Moreover, the AMLO permeation was significantly higher with $1.5 \mathrm{~mm}$ ADM when compared to 0.6 and $1.2 \mathrm{~mm}$ ADM $(p<0.05)$ even though the density of MNs is low, which is may be because of longer needle lengths which intern resulted in deeper skin penetration.

With the PM application, a 1.63 and 6.11 fold increase in the cumulative amount (48 h) of AMLO permeated was observed with PM-1 and PM-3 treatments respectively, when compared to passive permeation amounts. The lag times were found to be significantly lower for PM-3 when compared to passive and PM-1 treatments $(p<0.05)$. The AMLO flux values were found to be in the order of PM-3 > PM-1 > passive treatments $(p<0.05)$. A 5.23 and 1.46 fold increase in AMLO flux was observed with the PM-3 and PM-1 respectively, when compared to passive studies. A similar trend was observed with other permeation parameters like permeability and diffusion coefficient values (Table 4) with both the PM treatments. Even though, the skin penetration by PM device (with $0.6 \mathrm{~mm}$ array) was significantly greater when compared to $0.6 \mathrm{~mm} \mathrm{ADM}$, the overall permeation enhancement in terms of cumulative amount permeated etc. achieved with PM-1 was found to be closer to those of $0.6 \mathrm{~mm}$ ADM ( $p>0.05)$. This may be because the needle density of $0.6 \mathrm{~mm}$ ADM was greater when 
compared to PM-1 (Table 3), which may have compensated the variation in the extent of skin penetration among these MNs, and thus no significant variation in overall permeation enhancement was observed among these two MNs ( $p>0.05)$.

In case of the PM, a single application of array didn't cover the $1.77 \mathrm{~cm}^{2}$ surface area of the skin and hence in order to maintain the MN density closer to ADM of $0.6 \mathrm{~mm}$ length the arrays were applied three times at different places within a $1.77 \mathrm{~cm}^{2}$ skin area $(\mathrm{PM}-3)$ as shown in Fig. 1. As the needle density was increased with PM-3, the AMLO transdermal permeation increased markedly and was similar to that obtained with $1.5 \mathrm{~mm} \mathrm{ADM}(p>0.05)$. Moreover, it is intriguing to note although the needle density PM-3 (75 MNs) was significantly greater when compared to $1.5 \mathrm{~mm}$ ADM (31 MNs) the overall AMLO permeation enhancement was considerably greater with $1.5 \mathrm{~mm}$ ADM with significantly shorter lag times $(p<0.05)$, which may be because of deeper (vertical) penetration into skin. Even though the depth of the penetration was significantly lower with PM when compared to $1.5 \mathrm{~mm} \mathrm{ADM}$, the comparable permeation enhancement by PM-3 is may be because of higher needle density and also wider microconduits formed as evidenced by histological section images (Fig. 6).

The enhancement in AMLO permeation was found to be in the order of 1.5mm ADM $\geq$ PM-3 $>1.2 \mathrm{~mm} \mathrm{ADM}>0.6 \mathrm{~mm}$ ADM $\geq \mathrm{PM}-1>$ Passive. Even though, no correlation of AMLO skin content was observed with different MN treatments, significantly higher amounts of AMLO were found to be distributed in skin layers at the end of 48h with MN treated studies and is an indication of potential AMLO skin deposition.

Overall, the transdermal permeation enhancement of AMLO by MN application is a complex phenomenon and the permeation enhancement is dependent on the several aspects of the MN geometry like the shape/design, length and density etc.

\section{Scaling analyses}


Using scaling analyses, correlations were developed for ADM MNs (same type but differing in length) between the dimensionless parameters, namely the amount of AMLO permeated $\left(C_{t} / C_{s}\right)$ and skin thickness $(h / L)$ and surface area of skin $\left(S_{a} / L^{2}\right)$ in order to derive a better understanding on the effect of specific geometry parameters of $\mathrm{MN}$, like length (L), on overall permeation enhancement by MNs of same design (ADM) (Fig. 8 A, B respectively) [21, 22]. Eqs. 2 and 3 describe such relationships among the considered parameters within the given range. These correlations were determined for given thickness and surface area of skin while the MN length varies (0.6, 1.2 and $1.5 \mathrm{~mm})$.

$$
\begin{gathered}
\frac{C_{t}}{C_{s}}=5.957 \times 10^{-3}\left[\frac{h}{L}\right]^{-1.2206} \quad \text { for } \quad 0.8 \leq \frac{h}{L} \leq 2 \text {---- (2) } \\
\frac{C_{t}}{C_{s}}=0.112\left[\frac{S_{a}}{L^{2}}\right]^{-0.6103} \quad \text { for } \quad 78.5 \leq \frac{S_{a}}{L^{2}} \leq 491.5 \text {---- (3) }
\end{gathered}
$$

Good correlations $\left(\mathrm{R}^{2}>0.89\right)$ were observed between the dimensionless parameters $\left(\mathrm{C}_{t} / \mathrm{C}_{\mathrm{s}}\right.$ vs $h / L$ and $C_{t} / C_{s}$ vs $S_{a} / L^{2}$ ) (Fig. 8). These correlations can be used to predict the amount of AMLO permeated $\left(C_{t} / C_{s}\right)$ with high accuracy for other MN lengths in the range of $0.6-1.5$ mm with similar design as ADM.

\section{CONCLUSION}

Transdermal permeation enhancement of AMLO by MN application and the effects of various geometry parameters on the degree of such enhancement was studied in this investigation using two types of MN devices (ADM and PM). A significant enhancement in the transdermal permeation of AMLO across pig ear skin was observed with application of MNs. It was further noted that the type/shape, density and more importantly, the length of MNs (depth of penetration into skin) play a crucial role in the overall permeation enhancement of AMLO using this technique. It may be inferred that the transdermal delivery of AMLO in a painless and non-invasive manner may by possible using $\mathrm{MN}$ applications. However, the observed lag times and transdermal flux values suggest that a still higher enhancement in permeation may be required in order to achieve clinically significant 
levels of the AMLO more rapidly after application of the transdermal system. This investigation can form a basis for further studies (in vivo) and for optimization of various MN parameters to achieve successful delivery of AMLO via. MN assisted transdermal delivery systems and in continuation to this study further development on AMLO containing MNs is of good choice.

\section{DISCLOSURE OF POTENTIAL CONFLICTS OF INTEREST:}

This study was funded jointly by Department of Science and Technology (DST), Ministry of Science and Technology, Govt. of India and the British Council, London, UK, under DSTUKIERI scheme (DST/INT/UK/P-60/2014) to Buchi N. Nalluri and Diganta B. Das. All the authors declares that they have no conflict of interest.

\section{REFERENCES}

1. Brown MB, Gary PM, Stuart AJ, Franklin KA. Dermal and transdermal drug delivery systems: current and future prospects. Drug Delivery. 2006;13:175-187.

2. Prausnitz MR, Robert L. Transdermal drug delivery. Nat Biotechnol. 2008;26:12611268.

3. Nwankwo T, Yoon SS, Burt V, Gu Q. Hypertension among adults in the US: National Health and Nutrition Examination Survey, 2011-2012. NCHS Data Brief, No. 133. Hyattsville, MD: National Center for Health Statistics, Centers for Disease Control and Prevention, US Dept of Health and Human Services, 2013.

4. Lim SS, Vos T, Flaxman AD, Danaei G. A comparative risk assessment of burden of disease and injury attributable to 67 risk factors and risk factor clusters in 21 regions, 1990-2010: a systematic analysis for the Global Burden of Disease Study 2010. Lancet. 2012;380(9859):2224-60. 
5. Suchanova B, Kostiainen K, Ketola RA. Characterization of the in vitro metabolic profile of amlodipine in rat using liquid chromatography-mass spectrometry. European Journal of Pharmaceutical Sciences. 2008;33:91-99.

6. Hardman JG, Limbird LE. Goodman and Gilman's the pharmacological basis of therapeutics. New Delhi: McGraw Hill Medical Publishing Division, 10. 2001:853860.

7. McDaid DM, Deasy PB. Formulations development of a transdermal drug delivery system for amlodipine base. International Journal of Pharmaceutics. 1996;133:71-83.

8. Hemangi JP, Jitendra SP, Desai BG, Keyur DP. Permeability studies of antihypertensive drug amlodipine besilate for transdermal delivery. Asian Journal of Pharmaceutical and Clinical Research. 2010;3:31-34.

9. Sanju N, Kamal S, Bhavna Y, Benika S. Formulation and Characterization of Transdermal Patch of Amlodipine Besylate. International Journal of Pharmaceutical and Chemical Sciences. 2012;1:953-969.

10. Lincy J, Arun K. Comparison of amlodipine transdermal patches using hydroxypropylmethylcellulose and chitosan. Asian J Pharm. Clin. Res. 2014;7:86-90.

11. Han T, Das DB. Potential of combined ultrasound and microneedles for enhanced transdermal drug permeation: A review. Eur. J. Pharm. Biopharm. 2015;89:312-328.

12. Gill HS, Denson DD, Burris BA, Prausnitz MR. Effect of microneedle design on pain in human volunteers. Clin. J. Pain. 2008;24:585-594.

13. Jeong W, Lee A, Jung-Hwan PB, Prausnitz MR. Dissolving microneedles for transdermal drug delivery Biomaterials. 2008;29:2113-2124.

14. Zhou CP, Liu YL, Wang HL, Zhang PX, Zhang JL. Transdermal delivery of insulin using microneedle rollers in vivo. International Journal of Pharmaceutics. 2010;39:127-133. 
15. Nalluri BN, Sai Sri Anusha V, Bramhini SR, Amulya J, Sultana AS, Teja UC, Das DB. In vitro skin permeation enhancement of sumatriptan by microneedle application. Curr Drug Deliv. 2015;12:761-769.

16. Monika K, Kevin BI, Inna EP, Sanjai JP, Daniel AB. Microneedle-assisted delivery of verapamil hydrochloride and amlodipine besylate. European Journal of Pharmaceutics and Biopharmaceutics. 2014;86:284-291.

17. Gomaa YA, Morrow DI, Garland MJ, Donnelly RF, El-Khordagui LK, Meidan VM. Effects of microneedle length, density, insertion time and multiple applications on human skin barrier function: assessments by transepidermal water loss. Toxicol. In Vitro. 2010;24:1971-1978.

18. Chueng K, Han T, Das DB. Effect of force of microneedle insertion on the permeability of insulin in skin. J. Diabetes Sci. Technol. 2014;8:444-52.

19. Attia UM, Marsona S, Alcock JR. Micro-injection moulding of polymer microfluidic devices. Microfluidics and nano fluidics. 2009;7:1-28.

20. Nair KJ, Whiteside BR, Grant C, Patel R, Tuinea-Bobe C, Norris K, Paradkar AR. Investigation of Plasma Treatment on Micro-Injection Moulded Microneedle for Drug Delivery, Pharmaceutics. 2015;7:471-485.

21. Al-Qallaf B, Das DB, Mori D, Cui Z. Modelling transdermal delivery of high molecular weight drugs from microneedle systems. Phil. Trans. R. Soc. A. 2007;365:2951-67.

22. Leeladurga V, Teja UC, Ashraf SS, Sundeep K, Sai Sri Anusha V, Han T, Nalluri BN, Das DB. Application of microneedle arrays for enhancement of transdermal permeation of Insulin: in vitro experiments, scaling analyses and numerical simulations. AAPS Pharma Sci Tech. 2016;17(4):915-22. 
23. Vadim VY. 2010, US Patent No. 7658728 B2. Washington DC: U.S. Patent and Trademark Office. 


\section{CAPTIONS FOR FIGURES}

Fig. 1: Different MNs used in the study

Fig. 2: (A) Battenfeld micro-power 15 moulding machine; (B) 3D drawing of the microneedle insert

Fig. 3: (A) 3D confocal image of (a) front view of the PEEK MN array (b) Single MN of PEEK (c) line measurement of the PM array; (B) SEM image of (a) MN array of PEEK (b) top view of the needle (c) Single MN of PEEK; (C) 3D confocal image of $0.6 \mathrm{~mm}$ ADM showing its design parameters

Fig. 4: Solubility Data of AMLO in PG:S and PEG:S Solvent Systems

Fig. 5: Surface images of stained skin without and with MN treatment

Fig. 6: Penetration depth calculation of ADM and PM in skin (ToupView ${ }^{\circledR}$ screenshot)

Fig. 7: Comparative in vitro skin permeation profiles of AMLO from passive and MN treatments

Fig. 8: Scaling relationship of different dimensionless groups for permeation of AMLO - (A) Effects of dimensionless length of MNs; (B) Effects of dimensionless surface area for diffusion 
TABLES

Table 1. Micro-injection moulding parameters

\begin{tabular}{|l|c|}
\hline Parameter & PEEK \\
\hline Melt temperature $\left({ }^{\circ} \mathrm{C}\right)$ & 400 \\
\hline $\begin{array}{l}\text { Maximum injection velocity } \\
(\mathrm{mm} / \mathrm{s})\end{array}$ & 750 \\
\hline Clamping force $(\mathrm{kN})$ & 50 \\
\hline Holding pressure (bars) & 600 \\
\hline Mould base temperature $\left({ }^{\circ} \mathrm{C}\right)$ & 210 \\
\hline
\end{tabular}


Table 2. Model parameters for dimensional scaling analyses of the data

\begin{tabular}{|cc|}
\hline Parameter & Value \\
\hline Duration for medication: $\mathrm{t}_{\mathrm{m}}$ & $48 \mathrm{~h}$ \\
\hline Surface area of skin exposed: $\mathrm{S}_{\mathrm{a}}$ & $1.77 \mathrm{~cm}^{2}$ \\
\hline Thickness of stratum corneum: $\mathrm{h}_{\mathrm{sc}}$ & $0.002 \mathrm{~cm}$ \\
\hline $\begin{array}{c}\text { Total Thickness of membrane (distance } \\
\text { to blood vessel): } \mathrm{h}\end{array}$ & $0.12 \mathrm{~cm}$ \\
\hline Effective skin thickness: $\mathrm{h}_{\mathrm{e}}$ & Variable \\
\hline $\begin{array}{c}\text { Diffusion coefficient in viable skin: } \mathrm{D} \\
\text { Volume of Fluid in Receptor }\end{array}$ & Variable \\
Compartment (distribution): $\mathrm{V}_{\mathrm{d}}$ & 14 mL \\
\hline Skin surface/Donor concentration: $\mathrm{C}_{\mathrm{s}}$ & Saturated Solution was charged \\
& as the donor solution \\
\hline Microneedle length: $\mathrm{L}$ & $0.06,0.12$ and 0.15 cm \\
\hline
\end{tabular}


Table 3. Different geometry parameters of MNs used in the study

\begin{tabular}{|c|c|c|c|c|}
\hline \multirow{2}{*}{ Parameter } & \multicolumn{3}{|c|}{ ADM* } & \multirow[t]{2}{*}{$\mathbf{P M}$} \\
\hline & 0.6 & 1.2 & 1.5 & \\
\hline Length $(\mu \mathrm{m})$ & 600 & 1200 & 1500 & $560 \pm 30$ \\
\hline Number of MNs $\left(1.77 \mathrm{~cm}^{2}\right)$ & 187 & 41 & 31 & 25 \\
\hline Shape & \multicolumn{3}{|c|}{ Flat (2D) } & Conical (3D) \\
\hline Thickness of each MN $(\mu \mathrm{m})$ & \multicolumn{3}{|c|}{78 (uniform till tip)** } & 300 ( 30 at tip) \\
\hline Thickness of array base $(\mu \mathrm{m})$ & \multicolumn{3}{|c|}{$100-200^{* *}$} & 300 \\
\hline Material & \multicolumn{3}{|c|}{$\begin{array}{l}\text { Medical grade stainless steel } \\
\text { (SS 316L) }\end{array}$} & $\begin{array}{l}\text { PEEK LT-3 (polyether } \\
\text { ether ketone) }\end{array}$ \\
\hline
\end{tabular}

$*_{\text {values are from manufacturer }}^{23}$

**the width and thickness of the MN and the base varies with length 
Table 4. Permeation parameters of AMLO without and with MN treatments

\begin{tabular}{|c|c|c|c|c|c|c|}
\hline \multirow[b]{2}{*}{$\begin{array}{c}\text { Skin } \\
\text { treatment }\end{array}$} & \multicolumn{6}{|c|}{ Permeation Parameters } \\
\hline & $\begin{array}{c}\text { Cumulative } \\
\text { amount permeated } \\
\text { at } 48 \mathrm{~h}\left(\mathrm{nmoL} / \mathrm{cm}^{2}\right)\end{array}$ & $\begin{array}{c}\text { Steady state } \\
\text { flux } \\
\left(\mathrm{nmoL} / \mathrm{cm}^{2} / \mathrm{h}\right)\end{array}$ & Lag Time (h) & $\begin{array}{c}\text { Permeability } \\
\text { coefficient } \\
\left(\mathrm{x10}^{-05}\right) \\
(\mathrm{cm} / \mathrm{hr})\end{array}$ & $\begin{array}{c}\text { Diffusion } \\
\text { coefficient } \\
\left(\mathrm{x10}^{-10}\right) \\
\left(\mathrm{cm}^{2} / \mathrm{sec}\right)\end{array}$ & $\begin{array}{l}\text { Skin Content } \\
(\mu \mathrm{g} / \mathrm{g})\end{array}$ \\
\hline Passive & $293.069 \pm 28.646$ & $10.03 \pm 1.33$ & $19.12 \pm 1.06$ & $2.60 \pm 0.34$ & $8.68 \pm 1.15$ & $1351.55 \pm 281.43$ \\
\hline 0.6 ADM & $586.181 \pm 40.822$ & $19.10 \pm 2.10$ & $17.33 \pm 0.98$ & $4.96 \pm 0.54$ & $16.53 \pm 1.82$ & $1652.22 \pm 246.25$ \\
\hline 1.2 ADM & $1042.552 \pm 174.023$ & $29.96 \pm 4.80$ & $13.22 \pm 1.03$ & $7.78 \pm 1.25$ & $25.93 \pm 4.16$ & $1724.24 \pm 165.22$ \\
\hline 1.5 ADM & $2005.307 \pm 123.098$ & $53.04 \pm 4.43$ & $10.02 \pm 0.78$ & $13.77 \pm 1.15$ & $45.91 \pm 3.83$ & $2197.20 \pm 331.71$ \\
\hline PM-1 & $477.466 \pm 64.229$ & $14.65 \pm 1.00$ & $16.07 \pm 2.18$ & $3.81 \pm 0.26$ & $12.68 \pm 0.87$ & $1597.32 \pm 95.23$ \\
\hline PM-3 & $1791.853 \pm 165.519$ & $52.44 \pm 2.77$ & $13.69 \pm 1.34$ & $13.62 \pm 0.72$ & $45.39 \pm 2.40$ & $1880.74 \pm 151.62$ \\
\hline
\end{tabular}



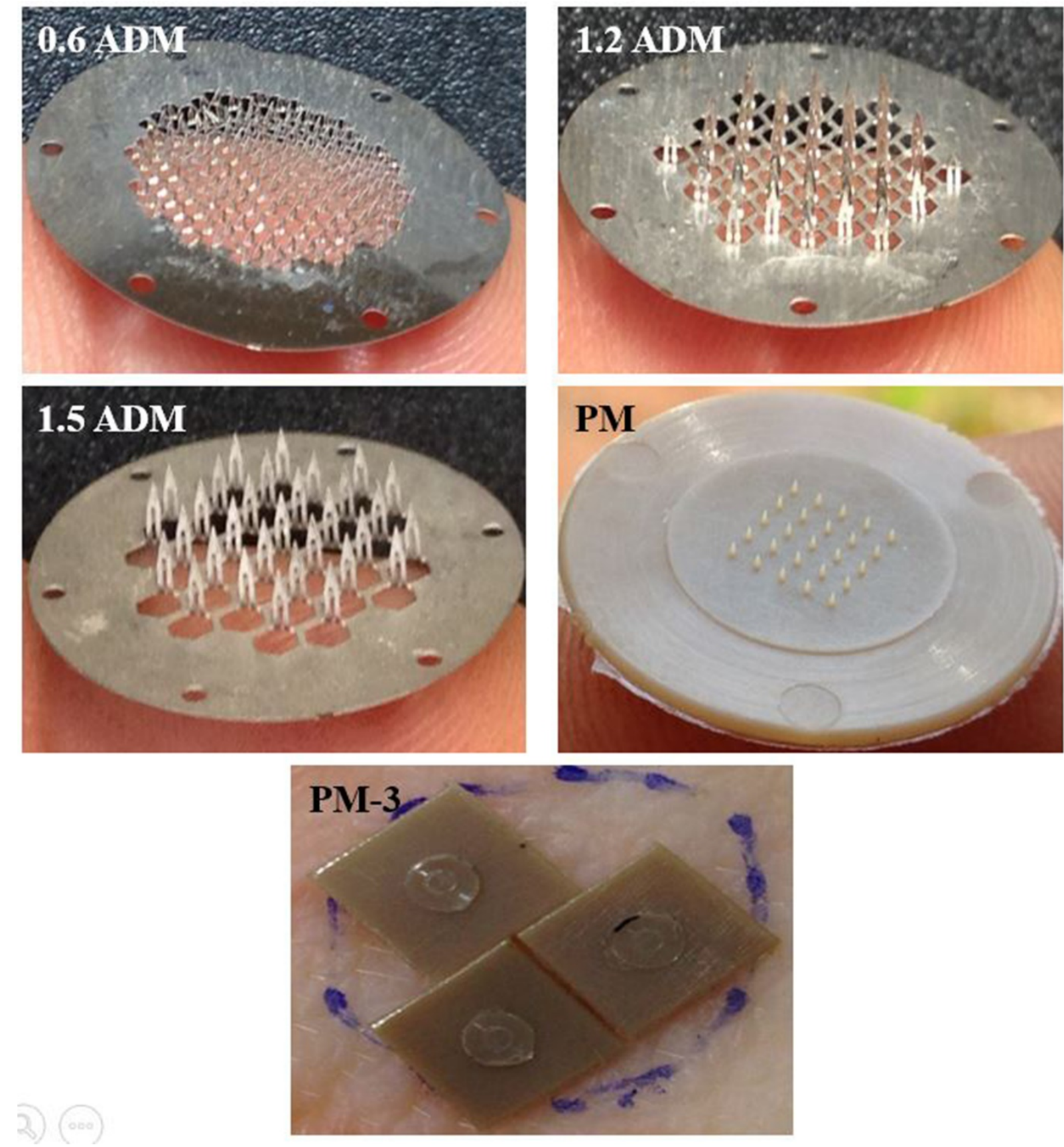

Fig 1 


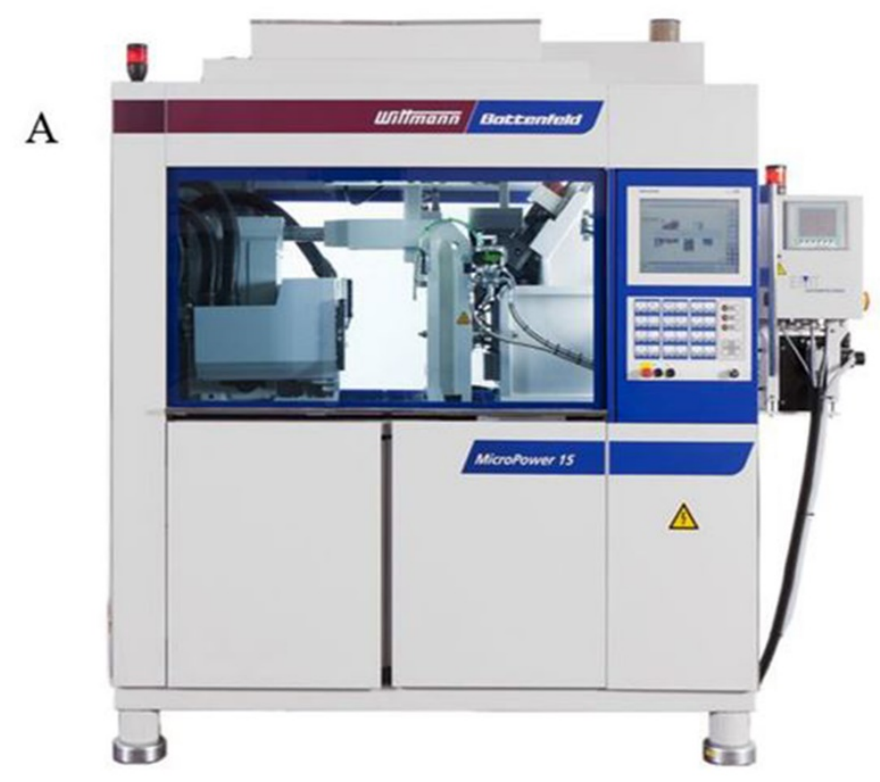

B

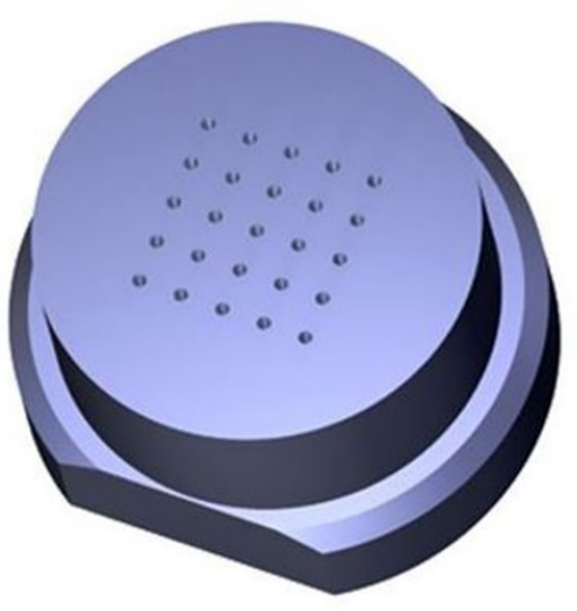

Fig 2 


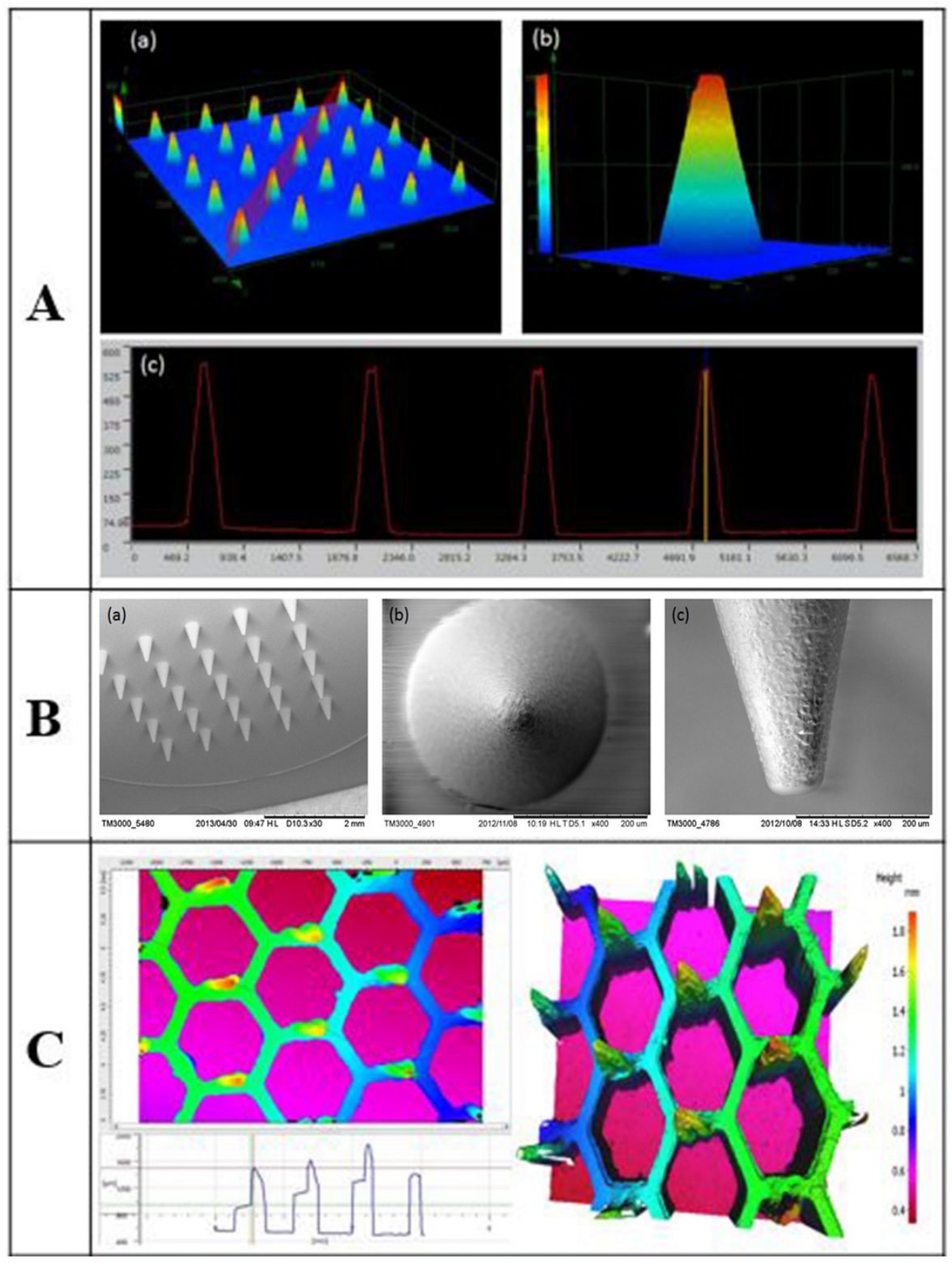

Fig3 


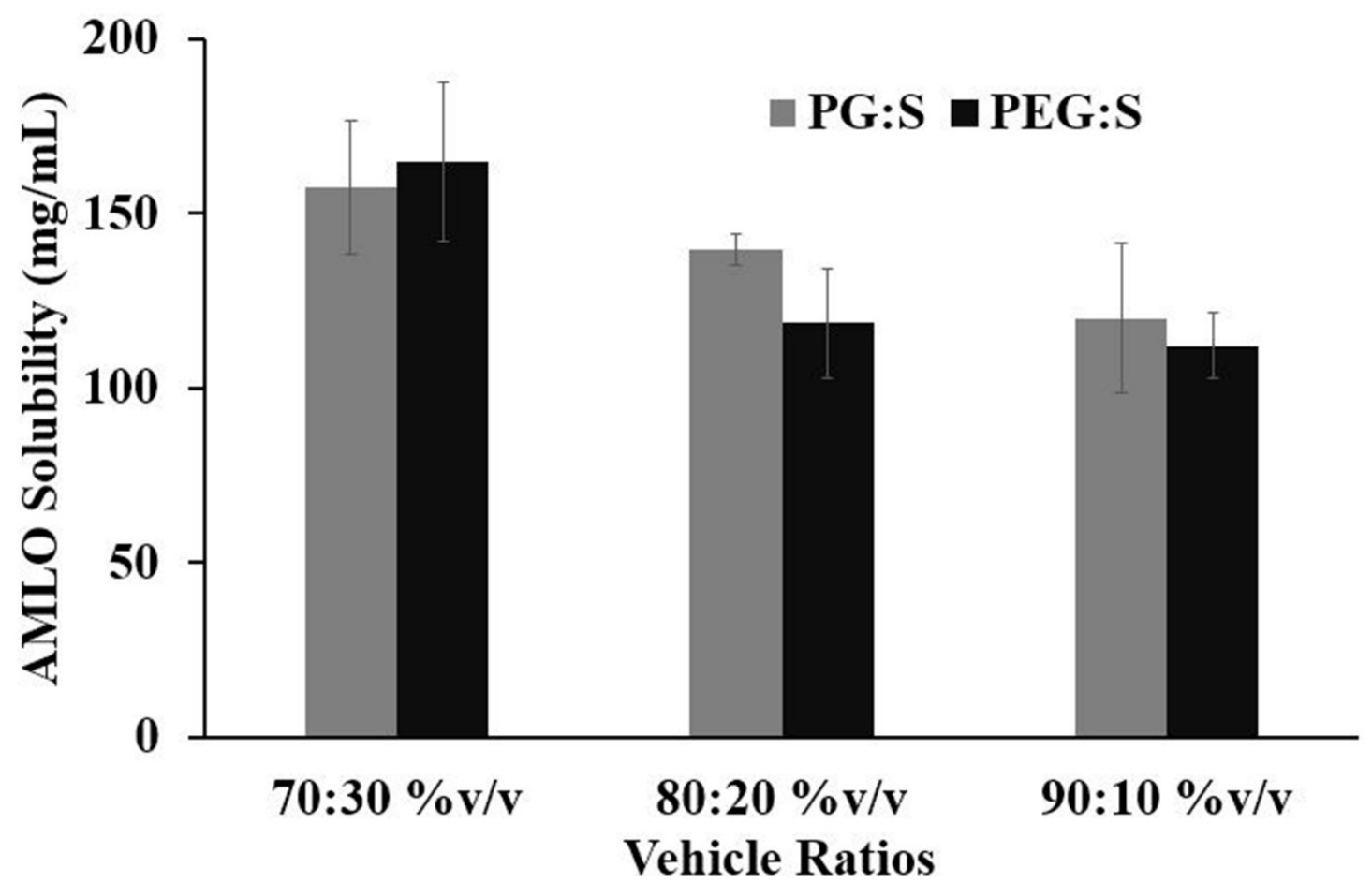

Fig 4 

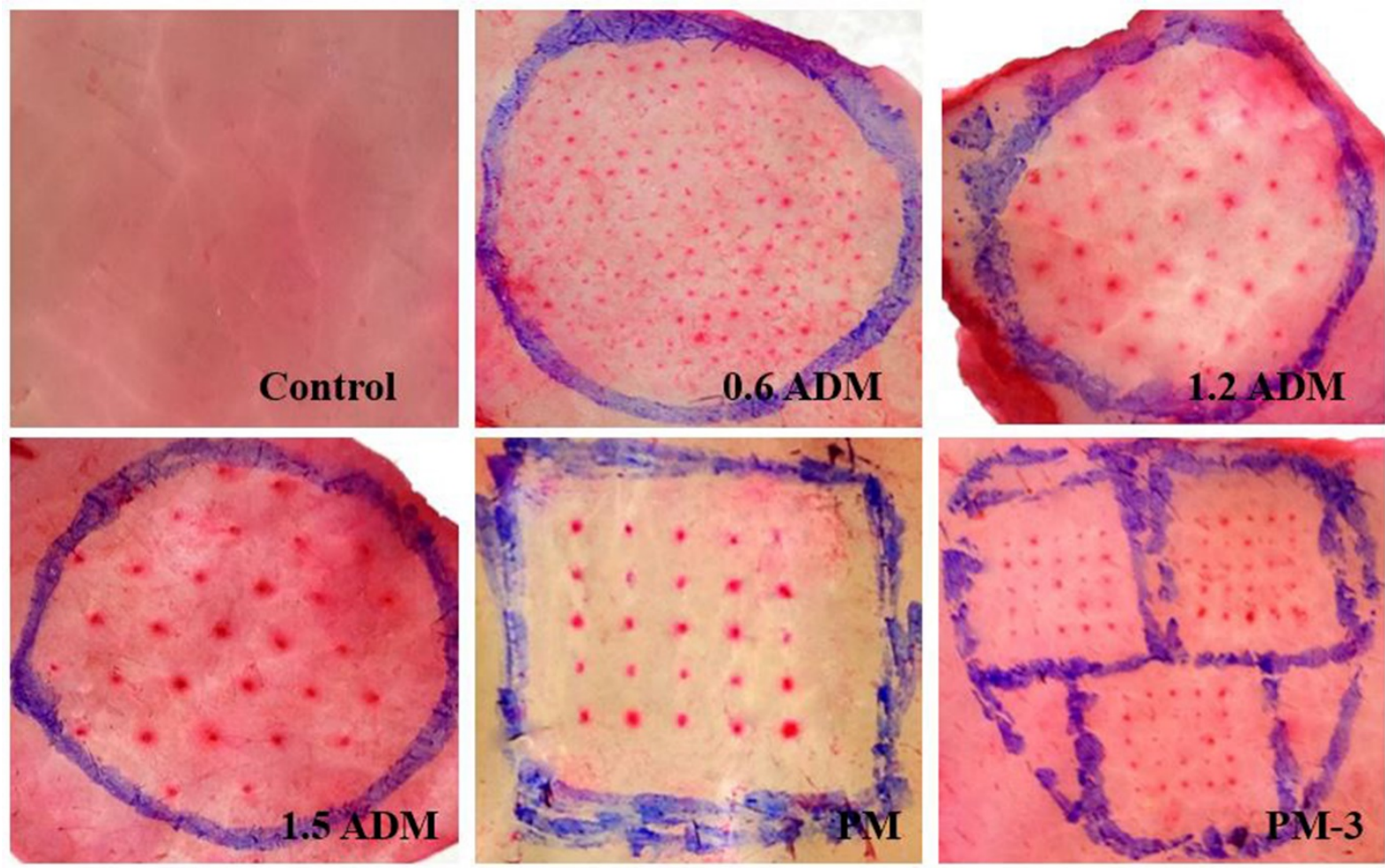

Fig 5 

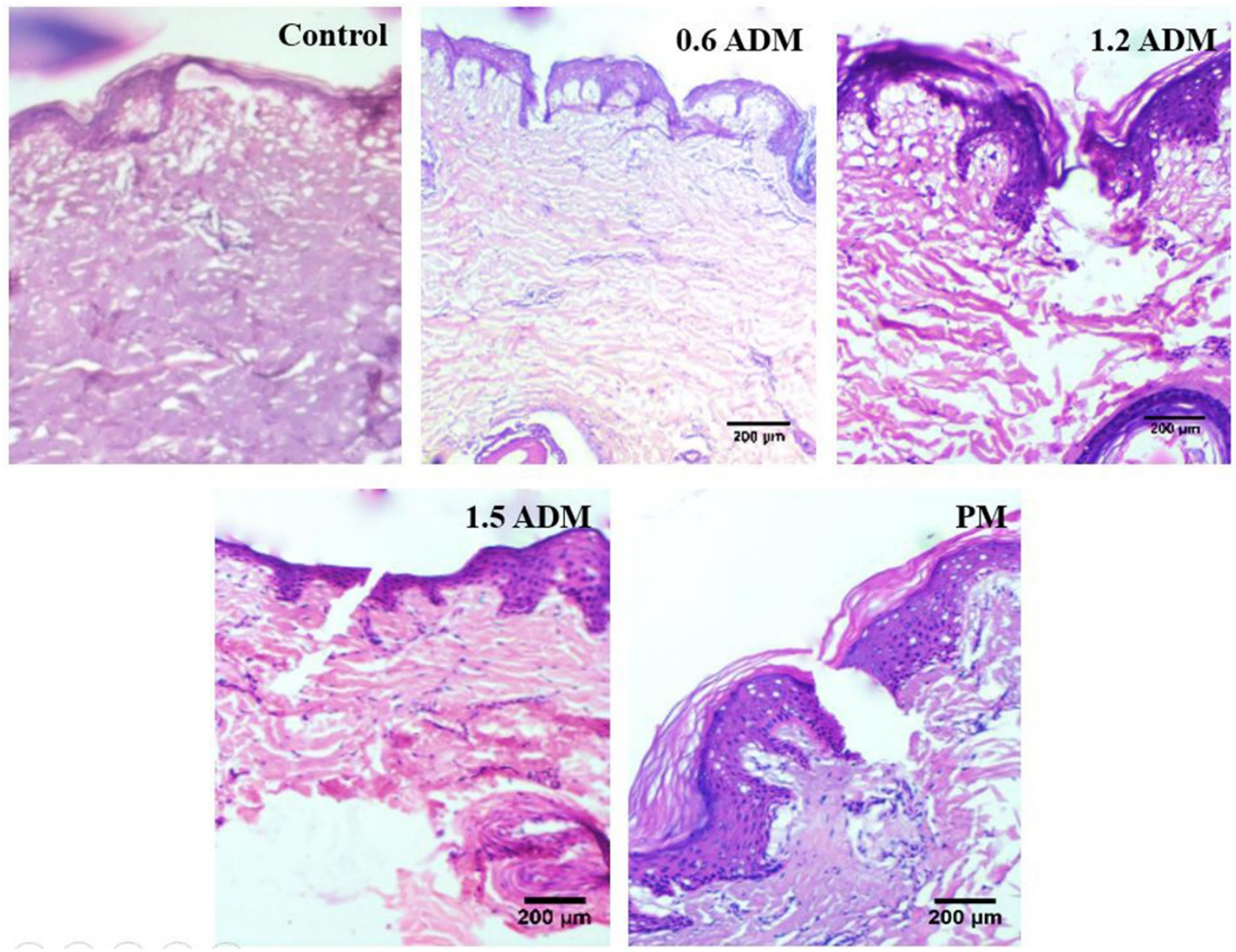

Fig 6 


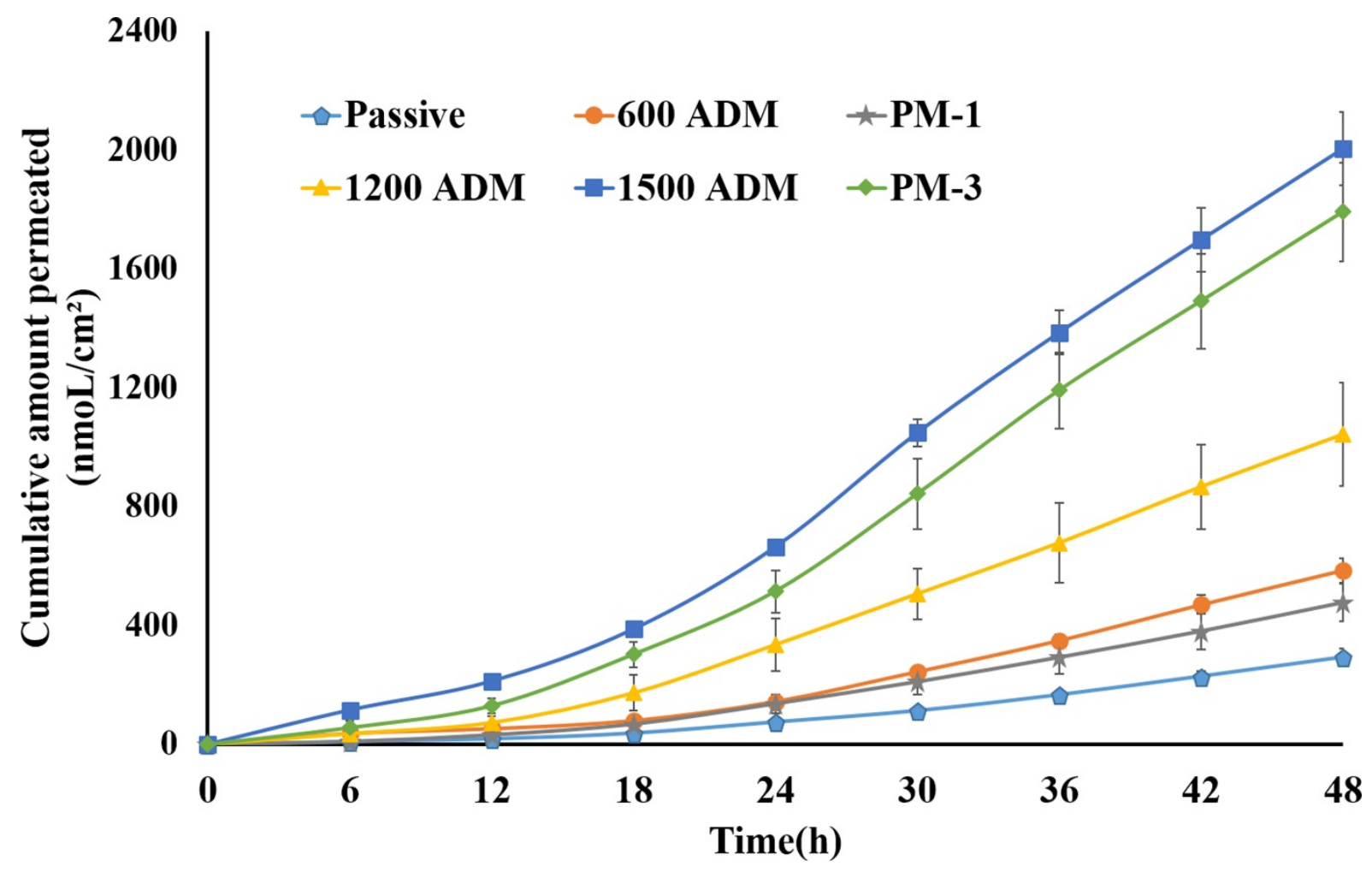

Fig 7 

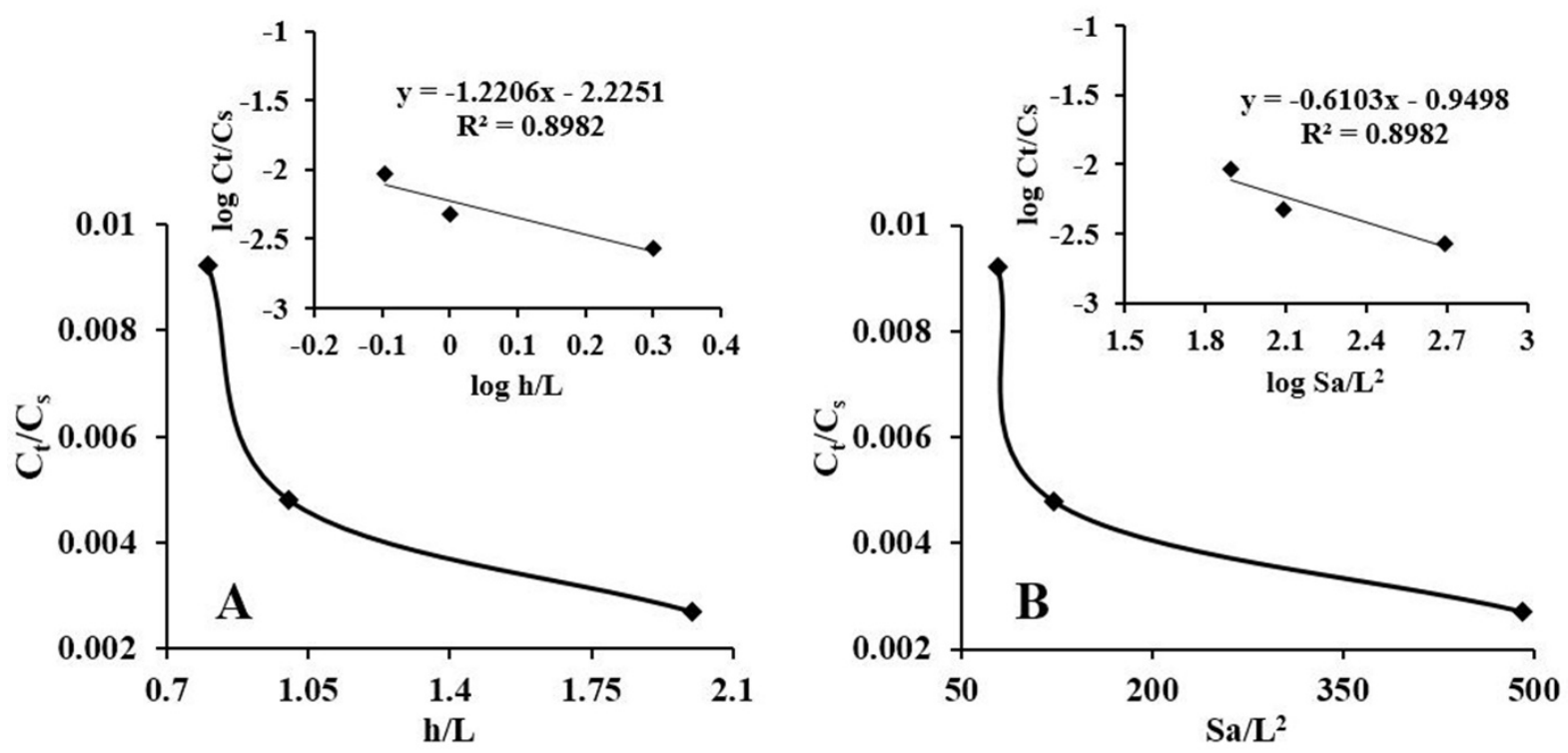

Fig 8 